\title{
Rescue strategies for refractory hypoxemia: a critical appraisal
} Jesús Villar ${ }^{1-3 *}$ and Robert M Kacmarek ${ }^{4,5}$

\author{
Addresses: ${ }^{1}$ CIBER de Enfermedades Respiratorias, Instituto de Salud Carlos III, Sinesio Delgado 6, 28029 Madrid, Spain; ${ }^{2}$ Multidisciplinary Organ \\ Dysfunction Evaluation Research Network, Research Unit, Hospital Universitario Dr. Negrin, Barranco de la Ballena, s/n - 4th Floor, South Wing, \\ 35010 Las Palmas de Gran Canaria, Spain; ${ }^{3}$ Keenan Research Center at the Li Ka Shing Knowledge Institute of St. Michael's Hospital, 30 Bond St, \\ Toronto, ON, M5B 1W8, Canada; ${ }^{4}$ Department of Anesthesia, Harvard Medical School, Boston, MA, USA; ${ }^{5}$ Department of Respiratory Care, \\ Massachusetts General Hospital, 55 Fruit Street, Ellison 401, Boston, MA 02114-2696, USA \\ * Corresponding author: Jesús Villar (jesus.villar54@gmail.com) \\ FI000 Medicine Reports 2009, I:91 (doi:I0.34I0/MI-9I)
}

The electronic version of this article is the complete one and can be found at: http://FI000.com/Reports/Medicine/content/I/9I

\begin{abstract}
Mechanical ventilation is the most important aspect of supportive care of patients with severe acute respiratory failure. Most research directed to improving the prognosis of these patients has focused on improving support of the injured lung. In this report, current knowledge on innovative ways to manage refractory hypoxemia and ventilation without further damaging the injured lung is briefly discussed.
\end{abstract}

\section{Introduction and context}

Acute respiratory failure due to severe acute lung injury (ALI) or the acute respiratory distress syndrome (ARDS) is one of the most challenging problems of patients in intensive care units (ICUs). For years, mechanical ventilation (MV), using conventional mechanical ventilators, was the only supportive form of therapy providing adequate oxygenation and carbon dioxide elimination. MV provides time for disease-specific therapy to reverse the cause of failure and for recovery of respiratory function. The adverse effects of conventional MV are the direct consequence of pulmonary pressure or volume changes induced by cyclic mechanical insufflations of diseased lungs or both. Specifically, high-peak alveolar pressures, cyclic opening and closing of unstable lung units, and high concentrations of oxygen can cause lung injury during MV.

The aim of this short review is to summarize the current literature on a number of alternative techniques (currently in use worldwide or under evaluation) to improve oxygenation and ventilation in ALI/ARDS patients with refractory hypoxemia. Today, refractory hypoxemia is rare and is an infrequent cause of death $(<10 \%$ of ARDS deaths). There is no standard definition for refractory hypoxemia in terms of a predetermined arterial partial pressure of oxygen $\left(\mathrm{PaO}_{2}\right)$ value under a specific oxygen concentration (fraction of inspired oxygen, or $\mathrm{FiO}_{2}$ ) and applied positive end-expiratory pressure (PEEP) level during a certain period of time. In most reports, it has been defined as having $\mathrm{PaO}_{2}$ of less than $60 \mathrm{~mm} \mathrm{Hg}$, an $\mathrm{FiO}_{2}$ of 0.8-1.0, and a PEEP of greater than $10-20 \mathrm{~cm}$ $\mathrm{H}_{2} \mathrm{O}$ for more than 12-24 hours. For the purpose of this article, we did not review current techniques that improve oxygenation by minimizing oxygen consumption, such as muscle paralysis [1], or that are designed to open collapsed alveoli early in the course of persistent ARDS, such as the use of recruitment maneuvers followed by a decremental PEEP trial [2,3]. A recruitment maneuver is defined as applying a pressure higher than that applied during a normal breath either intermittently (for 2-3 minutes) or sustained for a short period of time (up to about 40 seconds). In a recent meta-analysis [4] of seven clinical trials involving 1170 patients with ALI/ ARDS, there was no significant difference in survival between groups receiving an 'open-lung' ventilatory strategy that included recruitment maneuvers and groups given standard ventilatory care. However, the main limitation of that systematic review was the design of trials that either did not isolate recruitment maneuvers from other variables or assessed only short-term outcomes, and few of these trials determined the patient-specific 
PEEP level (by decremental trial) following the recruitment maneuvers, a key to the successful use of recruitment maneuvers.

\section{Recent advances \\ Extracorporeal membrane oxygenation}

This technique was originally applied in patients with acute respiratory failure of such severity that it was impossible to provide adequate oxygenation by conventional MV [5]. To supplement gas exchange, a portion of the cardiac output must go through the extracorporeal membrane oxygenation (ECMO) circuit. During ECMO, carbon dioxide is removed by the extracorporeal circuit, but this technique is usually supplemented with conventional MV at low ventilatory rates and high PEEP levels and with tidal volumes to maintain a plateau pressure of below $28 \mathrm{~cm} \mathrm{H}_{2} \mathrm{O}$. Most long-term adult ECMO [6] is performed using the venovenous approach. Access for both blood removal and return is via the femoral, saphenous, or jugular veins. Despite the excitement generated by earlier reports of success, the results of ECMO trials led to a loss of enthusiasm for its use in acute respiratory failure. However, some investigators believe that there exists a role for ECMO in young adult patients with single organ system failure who are deemed to have potentially reversible pulmonary dysfunction when all other conventional modalities have failed [7].

Recently, a large muticenter adult ECMO trial was completed. Referred to as the CESAR trial (Conventional ventilatory support versus Extracorporeal membrane oxygenation for Severe Adult Respiratory failure) [8], this randomized controlled trial (RCT) assessed the effectiveness of extracorporeal lung assist in 180 patients with severe ARDS. The results of this study [9] represent the first positive RCT on adult ECMO application in severe respiratory failure. Survival at 6 months or absence of severe disability was achieved in $63 \%$ of the ECMO patients compared with $47 \%$ of the control group $(P=0.03)$. However, there are a number of major concerns and limitations with this study. First, patients allocated to conventional management (control group) were treated with conventional MV or with highfrequency ventilation. Second, patients in the control group were ventilated with a nonstandardized protocol; to ensure the collaboration of participating centers, physicians were allowed to choose any ventilatory strategy. Third, $30 \%$ of patients in the control group were not ventilated with a lung-protective strategy. Fourth, no data regarding ventilatory parameters at study entry and during the MV period are presented. Fifth, all ECMO patients were treated in the same center. Sixth, the ECMO center did not treat patients randomly assigned to the conventional management group. Seventh, many patients randomly assigned to ECMO did not receive ECMO. In fact, 103 patients who were screened for eligibility were excluded because a bed was unavailable for ECMO and 22 patients (25\%) assigned to be transferred to the ECMO center never received ECMO (16 improved with conventional management). Finally, a more critical analysis of outcome data when comparing overall patients who actually received ECMO (68 out of $90)$ with those who were treated with $M V$ and had information about mortality (87 plus 22 ) showed that the mortality rates were similar in the two groups $(48.5 \%$ for ECMO versus $43.1 \%$ for MV) $(P=0.64$, calculated by JV and RMK). In addition, the ICU and hospital lengths of stay were more than double in the ECMO group.

\section{High-frequency oscillatory ventilation}

Our understanding of the mechanisms and importance of ventilator-induced lung injury has advanced over the last three decades. High-frequency oscillatory ventilation (HFOV) should theoretically be an ideal mode to ventilate patients with severe lung damage [10]. It achieves gas exchange by delivering very small tidal volumes (often less than the anatomic dead space) at frequencies ranging from 3 to $15 \mathrm{~Hz}$ around a relatively constant mean airway pressure. HFOV is not a difficult technique. In fact, it is easier than conventional MV: it incorporates fewer and simpler controls and they are not interrelated as they are in conventional mechanical ventilators. Recent prospective observational studies have reported that HFOV is a feasible and efficient method of ventilation that results in rapid and sustained improvement in oxygenation in patients with severe ARDS [11-14]. However, a critical examination of RCTs comparing HFOV with conventional ventilation demonstrates that there is equivalence between conventional ventilation and HFOV $[15,16]$. Specifically, there is no evidence that conventional MV with low tidal volumes, high PEEP, and limited plateau pressures is more harmful than HFOV. All of the RCTs to date have compared HFOV with a less-than-optimal approach to conventional ventilation [15]. However, there are at least two trials that are just beginning that promise to compare HFOV with more appropriately applied conventional ventilation.

\section{Prone positioning}

Changes in posture can have profound effects on the pulmonary function of patients with severe respiratory failure. Most changes in pulmonary physiology with posture occur due to the influence of gravity and chest wall shape on the mechanical properties of the lung. By tradition, patients with respiratory failure are cared for in a supine position. In critically ill patients, the supine 
posture is associated with a decrease in functional residual capacity (FRC) below the closing capacity, resulting in ventilation-perfusion mismatching and a drop in $\mathrm{PaO}_{2}$. During acute respiratory failure, a reduction of FRC results in supine hypoxemia regardless of age. The proposed mechanisms by which prone positioning improves oxygenation include an increase in FRC, a change in regional diaphragm motion, redistribution of perfusion to better ventilated lung units, redistribution of ventilation to better perfused lung units, and improved secretion clearance [17].

The act of turning is labor-intensive; at least three experienced staff members are required in order to avoid losing vascular accesses or the airway. Meticulous care must be used in positioning the patient. Placing a neck roll or a pillow under the patient's shoulders and turning the head to one side is the recommended way to support the patient when prone. In addition, prone positioning may require an increased need for sedation. Although complications such as skin injury, facial edema, catheter removal or compression, hypotension, arrhythmias, and extubation may occur, prone positioning in general can be performed safely if staff are appropriately trained.

Although there are sufficient data to conclude that oxygenation frequently improves when patients with ARDS are turned prone (in about $70 \%$ of patients), prone positioning is still not widely implemented. Three recent systematic reviews and a meta-analysis [18-20] in patients with ALI/ARDS have shown that prone positioning does not reduce mortality or duration of MV despite improved oxygenation and a decreased risk of pneumonia.

\section{Inhaled vasodilators}

Anti-inflammatory agents and vasodilators have been tried experimentally in animals and humans as prophylaxis or treatment of ARDS. Prostaglandins, ibuprofen, pentoxifylline, inhaled nitric oxide (iNO), inhaled prostacyclin, almitrine, and corticosteroids have all been tried. None of them has shown any major benefit on outcome in large randomized human trials, even though significant improvements in oxygenation have been observed with some of these agents [21].

$\mathrm{NO}$ is important for the regulation of pulmonary vascular smooth muscle. NO appears to be pivotal in acute and chronic hypoxic pulmonary vasoconstriction. Pulmonary hypertension is a typical feature of ARDS and is a bad prognostic factor in respiratory failure. iNO selectively dilates pulmonary vasculature without systemic effects [22]. Over the last 15 years, an increasing number of clinical studies assessing different aspects of iNO in ARDS patients and addressing the ability of NO to attenuate ALI have been published. In spite of the fact that many clinicians consider iNO a useful rescue treatment for ARDS patients, no RCT has demonstrated an outcome benefit. A recent systematic review and meta-analysis of 12 RCTs including a total of 1237 patients with severe ALI/ARDS found that, as a whole, $\mathrm{NO}$ is associated with limited improvement in oxygenation at 24 hours of therapy, has no effect on duration of ventilation, does not confer mortality benefits, and may cause harm [23].

\section{Implications for clinical practice}

As a result of this brief review of recent advances for the treatment of severe acute hypoxemic respiratory failure, our interpretation is that (a) there is not enough evidence to date from well-performed RCTs to routinely recommend the use of ECMO as rescue therapy in adults with severe ARDS, (b) there is no ventilatory mode (including HFOV) that has been proven to be superior to limiting end-inspiratory plateau pressures and tidal volumes and appropriately setting PEEP, (c) altering body position is part of the routine clinical care in most patients with respiratory failure but there is no evidence to support the routine use of prone positioning, and (d) none of the pharmacologic therapies evaluated in ALI/ARDS, including inhaled vasodilators, has been shown to reduce morbidity or mortality when compared with placebo or conventional treatment. The good news is that none of these therapies that improve oxygenation significantly increases morbidity or mortality. As a result, when conventional therapy fails, all can be considered. However, remember that the only thing they may accomplish is increasing costs!

\section{Abbreviations}

ALI, acute lung injury; ARDS, acute respiratory distress syndrome; ECMO, extracorporeal membrane oxygenation; $\mathrm{FiO}_{2}$, fraction of inspired oxygen; FRC, functional residual capacity; HFOV, high-frequency oscillatory ventilation; ICU, intensive care unit; iNO, inhaled nitric oxide; MV, mechanical ventilation; NO, nitric oxide; $\mathrm{PaO}_{2}$, arterial partial pressure of oxygen; PEEP, positive end-expiratory pressure; RCT, randomized controlled trial.

\section{Competing interests}

JV has received a research grant from Maquet (Rastatt, Germany). RMK has received research grants from Covidien (Loughlinstown, Ireland), GE Healthcare (Little Chalfont, Buckinghamshire, UK), Hamilton Medical AG (Bonaduz, Switzerland), Newport Medical (Costa Mesa, CA, USA), and Dräger (Lübeck, Germany), 
honorarium for lecturing from Covidien, and is a consultant for Newport Medical.

\section{Acknowledgment}

This work was supported in part by grants from the Spanish Ministry of Health (FIS 07/0113).

\section{References}

I. Gainnier M, Roch A, Forel JM, Thirion X, Arnal JM, Donati S, Papazian L: Effect of neuromuscular blocking agents on gas exchange in patients presenting with acute respiratory distress syndrome. Crit Care Med 2004, 32:I I3-9.

2. Borges JB, Okamoto VN, Matos GF, Caramez MP, Arantes PR, Barros F, Souza CE, Victorino JA, Kacmarek RM, Barbas CS, Carvalho CR, Amato MB: Reversibility of lung collapse and hypoxemia in early acute respiratory distress syndrome. $\mathrm{Am} J$ Respir Crit Care Med 2006, I 74:268-78.

FI000 Factor 6.6 Must Read

Evaluated by Niall Ferguson 25 Oct 2006, Harald Groeben 27 Dec 2006, Marcelo Gama de Abreu 05 Nov 2007, James Leatherman 20 May 2008

3. Girgis K, Hamed H, Khater Y, Kacmarek RM: A decremental PEEP trial identifies the PEEP level that maintains oxygenation after lung recruitment. Respir Care 2006, 5 I: I I32-9.

4. Hodgson C, Keating JL, Holland AE, Davies AR, Smirneos L, Bradley SJ, Tuxen D: Recruitment manoeuvres for adults with acute lung injury receiving mechanical ventilation. Cochrane Database Syst Rev 2009, 2:CD006667.

5. Egan TM, Duffin J, Glynn MF, Todd TR, DeMajo W, Murphy E, Fox L, Cooper JD: Ten-year experience with extracorporeal membrane oxygenation for severe respiratory failure. Chest 1988, 94:68I-7.

6. Zapol WM, Snider MT, Hill JD, Fallat RJ, Bartlett RH, Edmunds LH, Morris AH, Peirce EC 2nd, Thomas AN, Proctor HJ, Drinker PA, Pratt PC, Bagniewski A, Miller RG Jr: Extracorporeal membrane oxygenation in severe acute respiratory failure: a randomized prospective study. JAMA 1979, 242:2193-96.

7. Madershahian N, Wittwer T, Strauch J, Franke UF, Wippermann J, Kaluza M, Wahlers T: Application of ECMO in multitrauma patients with ARDS as rescue therapy. J Card Surg 2007, 22: I80-4.

8. Peek G, Clemens F, Elbourne D, Firmin R, Hardy P, Hibbert C, Killer $H$, Mugford $M$, Thalanany $M$, Tiruvoipati R, Truesdale A, Wilson A: CESAR: conventional ventilatory support vs. extracorporeal membrane oxygenation for severe adult respiratory failure. Health Serv Res 2006, 6:163.

9. Peek GJ, Mugford M, Tiruvoipati R, Wilson A, Allen E, Thalanany MM, Hibbert CL, Truesdale A, Clemens F, Cooper N, Firmin RK, Elbourne D; CESAR trial collaboration: Efficacy and economic assessment of conventional ventilatory support versus extracorporeal membrane oxygenation for severe adult respiratory failure (CESAR): a multicentre randomised controlled trial. Lancet 2009, 374: |35|-63.

Changes Clinical Practice

FI000 Factor 6.7 Must Read

Evaluated by Cesare Gregoretti 02 Oct 2009, Thomas Luecke 19 Oct 2009, Alain Vuylsteke 19 Oct 2009, Claude Guerin 04 Nov 2009
10. Ferguson ND, Villar J, Slutsky AS: Understanding high-frequency oscillation: lessons from the animal kingdom. Intensive Care Med 2007, 33:1316-18.

II. Ferguson ND, Chiche JD, Kacmarek RM, Hallett DC, Mehta S, Findlay GP, Granton JT, Slutsky AS, Stewart TE: Combining highfrequency oscillatory ventilation and recruitment manoeuvres in adults with early acute respiratory distress syndrome: the Treatment with Oscillation and an Open Lung Strategy (TOOLS) Trial pilot study. Crit Care Med 2005, 33:479-86.

12. Demory D, Michelet P, Arnal JM, Donati S, Forel JM, Gainnier M, Brégeon F, Papazian L: High-frequency oscillatory ventilation following prone positioning prevents a further impairment in oxygenation. Crit Care Med 2007, 35:106-II.

13. Fessler HE, Hess DR: Does high-frequency ventilation offer benefits over conventional ventilation in adults patients with acute respiratory distress syndrome? Respir Care 2007, 52:595-605.

14. Fessler HE, Hager DN, Brower RG: Feasibility of very highfrequency ventilation in adults with acute respiratory distress syndrome. Crit Care Med 2008, 36:1043-48.

15. Derdak S, Mehta S, Stewart TE, Smith T, Rogers M, Buchman TG, Carlin B, Lowson S, Granton J; Multicenter Oscillatory Ventilation For Acute Respiratory Distress Syndrome Trial (MOAT) Study Investigators: High-frequency oscillatory ventilation for acute respiratory distress syndrome in adults: a randomized, controlled trial. Am J Respir Crit Care Med 2002, 166:80I-8.

16. Bollen CW, Van Weil TJ, Sherry T, Beale RJ, Shah S, Findley G, Monchi M, Chiche JD, Weiler Uiterwaal CN, van Vught AJ: High frequency oscillatory ventilation compared with conventional mechanical ventilation in adult respiratory distress syndrome: a randomized controlled trial. Crit Care 2005, 9:R430-R439.

17. Lamm WJ, Graham MM, Albert RK: Mechanisms by which the prone position improves oxygenation in acute lung injury. Am J Respir Crit Care Med 1994, I 50: I84-93.

18. Sud S, Sud M, Friedrich JO, Adhikari NK: Effect of mechanical ventilation in the prone position on clinical outcomes in patients with acute hypoxemic respiratory failure: a systematic review and meta-analysis. CMAJ 2008, I78: I I53-6I.

19. Abroug F, Ouanes-Besbes L, Elatrous S, Brochard L: The effect of prone positioning in acute respiratory distress syndrome or acute lung injury: a meta-analysis. Areas of uncertainty and recommendations for research. Intensive Care Med 2008, 34: $1002-11$.

20. Kopterides P, Siempos II, Armaganidis A: Prone positioning in hypoxemic respiratory failure: meta-analysis of randomized controlled trials. J Crit Care 2009, 24:89-100.

21. Raghavendran K, Pryhuber GS, Chess PR, Davidson BA, Knight PR, Notter RH: Pharmacotherapy of acute lung injury and acute respiratory distress syndrome. Curr Med Chem 2008, I 5: 191 I-24.

22. Dinh-Xuan AT: Endothelial modulation of pulmonary vascular tone. Eur Respir J 1992, 5 I:757-62.

23. Adhikari NK, Burns KEA, Friedrich JO, Granton JT, Cook DJ: Effect of nitric oxide on oxygenation and mortality in acute lung injury: systematic review and meta-analysis. BMJ 2007, 334:779.

FI000 Factor 3.0 Recommended Evaluated by Niall Ferguson 19 Jun 2007 